\title{
Preliminary Results on the Effects of CD40/CD40L Interactions and SAC-induction on IFN- $\gamma$ Expression in Human Schistosomiasis
}

\author{
Silvia ML Montenegro/ ${ }^{+}$, Frederico GC Abath, Ana LC Domingues*, \\ Wlademir Melo, Clarice NL de Morais, Eridan M Coutinho, \\ Siddhartha Mahanty**, Thomas Wynn***
}

\begin{abstract}
Centro de Pesquisas Aggeu Magalhães-Fiocruz, Av. Morais Rego s/noㅡ, Cidade Universitária, 50670-420 Recife,
PE, Brasil *Universidade Federal de Pernambuco, Recife, PE, Brasil **Centers for Disease Control and Prevention, Atlanta, GA, USA ***National Institutes of Health, Bethesda, USA
\end{abstract}

In this communication the authors analyzed the pattern of expression of IFN- $\gamma$ as a surrogate type 1 response in different clinical forms of schistosomiasis in response to stimulation involving $T$-cell dependent and T-cell independent pathways, to investigate which pathways were functional in human schistosomiasis, and to further characterize the nature of Th1 response impairment in this parasitic disease.

Key words: Schistosoma mansoni - CD40/CD40 ligand - human schistosomiasis - IFN- $\gamma$

In murine schistosomiasis infection studies have shown that the CD4+ T helper cell responses evolve from a Th1 to a Th2 dominated response and that this transition to the Th2 type cytokine expression coincides with egg production by the adult parasites (Grzych et al. 1991, Pearce et al. 1992, Wynn et al. 1993). While the Th1 cytokine IFN- $\gamma$ and activated macrophages have been correlated with immunity in mice (James 1986, Sher et al. 1990). Th2 cytokines inhibit macrophage activation (Oswald et al. 1992) and have been implicated in granuloma formation around tissue deposited eggs (Chensue et al. 1992, Wynn et al. 1993). In human studies it was noted an impaired balance of Th2 and Th1 cytokine production (Williams et al. 1994), suggesting there is not a global suppression of Th1 response in humans but it is possible that the nonsynchronous nature of human infections which often stem from multiple parasite may obscure any Th1 cytokine response (Mahanty et al. 1992, Ribeiro de Jesus et al. 1993, King et al. 1993).

\footnotetext{
This work was supported by World Health Organization, Special Programme for Research and Training in Tropical Diseases.

${ }^{+}$Corresponding author. Fax:+55-81-453.1911. E-mail: silvia@cpqam.fiocruz.br

Received 14 May 2001

Accepted 25 July 2001
}

IL-12 is important in the differentiation of $\mathrm{T}$ naive CD4+ cells toward an IFN- $\gamma$ producing Th1 type cell, as well as in enhancing cytotoxic $\mathrm{T}$ cell mediated lysis and natural killer (NK) cell activity (McDyer et al. 1998). The mechanisms underlying the regulation of IL-12 are of most importance. One of the mechanisms involves the enhancement of IL-12 production by IFN- $\gamma$ : (a)directly inducing IL12 p35 transcription from peripheral blood mononuclear cells; (b) increasing expression of CD40 ligand stimulation; (c) downregulating IL-10. A second mechanism of IL-12 production is T-cell dependent, involving the interaction of CD40L expressed on T cells with its counterreceptor, CD40 on APCs. Finally, certain microorganisms or bacterial products can directly induce IL-12 (Chougnet et al. 1998).

The patients selected for the study, displayed, intestinal, hepato-intestinal and hepatosplenic clinical forms of schistosomiasis mansoni as defined previously by ultrasound (Domingues et al. 1993). The control group were from non-endemic areas of Brazil and North America. All human studies described were reviewed by ethical and scientific review boards overseeing both the USA and Brazilian teams.

The production of IFN- $\gamma$ was analyzed after stimulation of whole blood cell cultures (WBCC) with the stimuli Staphylococcus aureus Cowan strain (SAC), IL-10, anti-IL-10, LPS and CD40L ex- 
pressed by recombinant fibroblast cell line whereas fibroblasts expressing surface CD32 were used as controls. The whole blood was drawn with heparin $(10 \mathrm{U} / \mathrm{ml})$, diluted 1:3 in RPMI plus penicillin (100 $\mathrm{U} / \mathrm{ml})$ and streptomycin $(100 \mu \mathrm{g} / \mathrm{ml})$ and cultures were maintained in a humidified atmosphere with $5 \% \mathrm{CO}_{2}$. The supernatants were collected at $96 \mathrm{~h}$ and stored at $-70^{\circ} \mathrm{C}$ for subsequent determination of cytokine production. The measurement of IFN- $\gamma$ cytokines was performed by ELISA using specific capture and detection mAbs following previously published protocols (Williams et al. 1994, Montenegro et al. 1999). All statistical comparisions were made by use of a paired student $t$ test or, for unpaired data, the student $t$ test for independent samples. $\mathrm{P}<0.05$ was considered significant.

Chronic hepatosplenic patients produced less IFN- $\gamma$ when compared with SAC-stimulated uninfected individuals. In addition, only normal control and hepatointestinal groups expressed significantly more IFN- $\gamma$ in comparison with the unstimulated groups $(p<0.05)$. Interestingly, SAC induced IFN- $\gamma$ production was increased in normal controls and hepatointestinal groups $(\mathrm{p}<0.05)$ in comparison to SAC-stimulated cultures treated with anti IL-10 suggesting that SAC-induced IL-10 was partially antagonizing IFN- $\gamma$ production. We also studied if the CD40-CD40L pathway, involved in the T cell-dependent activation of APCs was functional in schistosomiasis. Surprisingly, chronic schistosomiasis patients were more responsive to CD40L stimulation and produced significantly more IFN- $\gamma$ in response to exogenous rIL-12 than normal controls, suggesting that the defect in SAC-induced IFN- $\gamma$ production was not attributable to an inability of patient $\mathrm{T}$ cells to respond to either Th1inducing factor. Chronic schistosomiasis patients produced more IL-12 in response to SAC, SAC+IFN- $\gamma$, or SAC/IFN- $\gamma /$ CD40L stimulation than normal controls, indicating that the impairment was also not due to a decrease in IL-12 production. These findings demonstrate that chronic schistosomiasis patient WBCC display a generalized deficiency in SAC-induced IFN- $\gamma$ expression which is unrelated to specific defects in IL-12 production or CD40/CD40 ligand interactions. This was particurlarly marked in the severe hepatosplenic form of the disease, suggesting the defect progresses with the evolution of the disease. We are currently trying to understand the courses of the deficiency and the relationship with the pattern of expression of other relevant cytokines.

\section{REFERENCES}

Chensue SW, Terebuh PD, Warmington KS, Hershey SD, Evanoff HL, Kunkel SL, Higashi GI 1992. Role of IL-4 and IFN- $\gamma$ in Schistosoma mansoni egg induced hypersensitivity granuloma formation. Orchestration, relative contribution and relationship to macrophage function. J Immunol 148: 900-906.

Chougnet C, Thomas E, Landay AL, Kessler HA, Buchbinder S, Scheer S, Shearer GM 1998. CD40 ligand and IFN- $\gamma$ synergistically restore IL- 12 production in HIV-infected patients. Eur J Immunol 28: 646-656.

Domingues ALC, Lima AR, Dias HS, Leão GC, Coutinho A 1993. An ultrasonographic study of liver fibrosis in patients infected with Schistosoma mansoni in Northeast Brazil. Trans R Soc Trop Med Hyg 87: 555-558

Grzych JM, Pearce EJ, Cheever A, Caulada ZA, Caspar P, Heiny S, Lewis F, Sher A 1991. Egg deposition is the major stimulus for the production of $\mathrm{Th} 2$ cytokines in murine schistosomiasis mansoni. $J$ Immunol 146: 1322-1327.

James SL 1986. Induction of protective immunity against Schistosoma mansoni by a non living vaccine. III. Correlation of resistance with induction of activated larvicidal macrophages. J Immunol 36: 3872-3877.

King CL, Low CC, Nutman TB 1993. IgE production in human helminth infection. Reciprocal interrelationship between IL-4 and IFN- $\gamma$. J Immunol 150: 18731880.

Mahanty S, Abrams JS, King CL, Limaye AP, Nutman TB 1992. Parallel regulation of IL-4 and IL-5 in human helminth infections. J Immunol 148: 3567-3571.

McDyer JF, Goletz TJ, Thomas E, June CH, Seder RA 1998. CD40 ligand/CD40 stimulation regulates the production of IFN- $\gamma$ from human peripheral blood mononuclear cells in an IL-12 and/or CD28 dependent manner. J Immunol 160: 1701-1707.

Montenegro SML, Miranda P, Mahanty S, Abath FGC, Teixeira KM, Coutinho EM, Brinkman J, Gonçalves I, Domingues LAW, Domingues ALC, Sher A, Wynn TA 1999. Cytokine production in acute versus chronic human schistosomiasis mansoni: the cross regulatory role of IFN- $\gamma$ and IL-10 in the responses of periferal blood mononuclear cells and splenocytes to parasite antigens. J Infect Dis 179: 1502-1514.

Oswald IP, Wynn TA, Sher A, James SL 1992. IL-10 inhibits macrophage microbicidal activity by blocking the endogenous production of tumor necrosis factor a required as $\alpha$ costimulatory factor for IFN$\gamma$ induced activation. Proc Natl Acad Sci USA 89: 8676-878.

Pearce EJ, Caspar P, Grzych JM, Lewis FA, Sher A 1992. Downregulation of Th1 cytokine production accompanies induction of Th2 responses by a parasitic helminth. J Exp Med 173: 159-166.

Ribeiro de Jesus AM, Almeida RP, Bacellar O, Araújo MI, Demeure C, Bina JC, Dessein AJ, Carvalho EM 1993. Correlation between cell mediated immunity and degree of infection in subjects living in an endemic area of schistosomiasis. Eur J Immunol 23: 152-158.

Sher A, Coffman RL, Hieny S, Cheever AW 1990. Ablation of eosinophil and IgE responses with anti-IL-5 
or anti-IL-4 antibodies fails to affect immunity against Schistosoma mansoni in the mouse. $J$ Immunol 145: 3911-3916.

Williams ME, Montenegro SML, Domingues ALC, Wynn TA, Teixeira K, Mahanty S, Coutinho A, Sher A 1994. Leukocytes of patients with Schistosoma mansoni respond with a Th2 pattern of cytokine production to mitogen or egg antigens but with Th0 pattern to worm antigens. J Infect Dis 170: 946-954. Wynn TA, Eltoum I, Cheever AW, Lewis FA, Gause WC, Sher A 1993. Analysis of cytokine mRNA expression during primary granuloma formation induced by eggs of Schistosoma mansoni. J Immunol 151: 1430-1440. 
106 CD40/CD40L and SAC-induction in Schistosomiasis - Silvia ML Montenegro et al. 